International Journal of Instruction e-ISSN: 1308-1470 • www.e-iji.net
July $2020 \bullet$ Vol.13, No.3

p-ISSN: 1694-609X

pp. $571-586$

Received: 04/10/2019

Revision: 15/02/2020

Accepted: 21/02/2020

OnlineFirst:03/05/2020

\title{
Values of Tolerance in Relation to Academic Achievements, Cultures, and Gender among UAE Universities Students
}

\author{
Salwa Al Majali
}

Al Ain University, United Arab Emirates, salwa.almajali@aau.ac.ae

Khalid AlKhaaldi

Al Ain University, United Arab Emirates, khalidalkhaaldi@yahoo.com

In the modern society of the twenty-first century, the values of tolerance, respect and openness are the basis for the successful development of the individual, so it is important to properly shape the attitude towards them among students during their university studies. This study is aimed to identify the values of tolerance of university students in relation to academic achievements and study variables in the United Arab Emirates. The descriptive and correlative approaches are used, as they are relevant for the study. The questionnaire was used as a tool for data collection, the sample of the study consisted of 200 students from different universities in the UAE. The results show that the respondents have a tolerance of $83.5 \%$ in the following order: positive competition, softness, peace with oneself, social responsibility, openness, cultural diversity, assistance, participation, altruism, respect and appreciation, peace with others, equality and finally justice. The results of the study also indicate a positive correlation between the values of tolerance. Moreover, as the results indicate, there are statistical differences in the tolerance level of females, which is higher than the average tolerance among males. The results also indicate that there are statistically significant differences in tolerance among students, due to the culture variable in favor of UAE nationality. The results also show that there are no statistically significant differences in tolerance among the students due to the variable of the year of study.

Keywords: values, tolerance, academic achievement, university students, culture

\section{INTRODUCTION}

In today's evolving world, people have become more aware of the need to stop the destruction of human values and ensure peaceful coexistence alongside development. However, maintaining moral values may be difficult because they are linked to the personality and cultural background of individuals, as well as other life conditions. This

Citation: AlMajali, S., \& AlKhaaldi, K. (2020). Values of Tolerance in Relation to Academic Achievements, Cultures, and Gender among UAE Universities Students. International Journal of Instruction, 13(3), 571-586. https://doi.org/10.29333/iji.2020.13339a 
applies to human relations between individuals within academic institutions. Hence, the current study was created to shed light on the extent to which university students have the values of tolerance and their role in increasing the student's motivation towards achieving scientific goal.

Intercultural communicative tolerance is considered to be one of the individual's significant social and professional qualities which are in demand of the modern society (Beketova et al., 2018). The importance of intercultural communicative tolerance formation is caused not only by the processes of globalization of professional mobility in the modern world, but also the need to create comfortable coexistence of students in the university multilingual educational environment, to reduce conflicts and to prevent the clash of cultures - bearers of various systems of values and standards.

The problem of understanding the tolerance, which has fundamental importance especially for the system of education, lies at the heart of cross-cultural sustainability of multiethnic societies (Karpov, 2016). The crisis of multiculturalism has revealed the problematic nature of understanding tolerance from the perspective of positive interactions with the ethnically different.

Tolerance is a moral principle and virtue. Tolerance means that one should treat others in the same way, as one needs others to treat him/her. Tolerance is also essential for ensuring the functioning of society and protecting nationalities, ethnic groups and the like from dangerous political ideologies. Tolerance is to act fairly, objectively and leniently towards those with whom one may disagree in beliefs, customs and cultural background, which means freedom from intolerance (Zolotukhin, 2001). The virtue of tolerance includes all the moral values, ensures the development of the progressive society and embodies the meanings of humanity.

Higher education institutions are part of society, and they are the largest community of young people who are the future and real wealth of the nation (Belyakova \& Zakharova, 2019). Therefore, it is necessary to emphasize the role of higher education institutions in the development of the country and the promotion of peace in society by instilling principles and values of tolerance among students. The dissemination of the values of tolerance among the students themselves has a great role in the continuation of achieving the scientific goal, which will be reflected in their access to hard and creative work associated with the development of civilization and scientific development, knowledge and culture of the homeland.

\section{Tolerance}

The importance and value of tolerance do not depend on simple relationships between people. Tolerance is an urgent societal need and the foundation of all human societies. The moral and realistic image of tolerance is reflected in all systems of society, their progress and development. With the absence of this societal value, there will be the concepts of violence, intolerance and extremism, disrupting interests and destabilizing factors of security and stability, and the prevalence of imposed opinions (Yevdokimova, 2008). Recognized by UNESCO as respect, acceptance and appreciation of rich diversity, openness, communication, freedom of thought, conscience and belief, and 
harmony in the context of differences, it is not only a moral imperative, but also a fundamental and legal duty, and tolerance is the virtue that facilitates peace in cultures of war (UNESCO, 1994).

Based on this concept, His Highness Sheikh Khalifa bin Zayed Al Nahyan, President of the State, announced the 2019 to be the year of tolerance in the country and gave the tolerance status to the UAE capital. This unique and great human value is believed to be an important one for all humankind. Therefore, all educational institutions should devote, promote and consolidate the culture, concepts and principles of the values of tolerance among students in order to contribute positively to making the value of tolerance a sustainable institutional act.

Tolerance is one of the key positive human concepts that has made its way into the history of humanity and has given it more peace in a world full of shortcomings. As a concept, tolerance has many cognitive accumulations reflected in the multiplicity of trends and ideologies (Zrouwali, 2016).

Therefore, tolerance can be seen as a fast-acting psychological treatment, if the heart is busy with tolerance and the mind is preoccupied by being soft and overlooking the mistakes of others, there will be peace, goodness and justice among people. Tolerance deepens human relations (Zrouwali, 2016). A study was carried out by both Lauer and Parvira (Lawler-Row \& Piferi, 2006) that indicated that more tolerant individuals are less depressed, anxious, more religious, happier and more satisfied with life, and tolerance improves the quality of life and satisfaction, and supports their enjoyment (Zrouwali, 2016). Experts also suggest that tolerance and forgiveness are necessary because they have a positive impact on human health, while hatred, revenge may cause heart problems and weaken the body's immunity to become susceptible to various diseases (Lawler, 2005).

\section{Tolerance and knowledge}

Tolerance is central to our political, social, cultural and scientific life. One of the commendable human behaviors. The values of tolerance form the basis of cognitive behavior, such as problem solving skills and positive thinking. These concepts are an essential part of human knowledge and are an educational goal in all stages of learning and education (AL Heelah,2000).

Pettigrew and Tropee (2006) have pointed out that direct contact between multicultural youth within educational institutions provides them with positive experiences, which will eventually lead to more positive attitudes towards society. Therefore, those in charge of educational institutions should provide the best conditions for positive communication between students because each contribution is an addition to the knowledge base on determinants of tolerant attitudes.

In addition, the strategic goals of education according to the (European Commission 2015) must promote cultures, values and respect for fundamental rights. Along with combating all forms of discrimination, and equipping all young people to interact positively with peers from diverse backgrounds and develop tolerant and positive 
attitudes towards others, with the ultimate goal of increasing social cohesion of society. Some studies have indicated that the largest contributor to the consolidation of the values of tolerance in individuals is higher education institutions. In a study conducted by Bobo and Lecari (1989) in the United States, they found a strong relationship between the years of education and tolerance among the members of the study. The results indicated that the higher the education of the individual the higher his/her values of tolerance, and the lower the education of the individual the more negative results were indicated.

The authors recognize that higher education institutions do not only aim at graduating individuals with scientific degrees only. One of their main goals is to educate and develop learners to participate in social, cultural and economic development processes, and encourage them to develop positive behaviors in order to contribute to the stability of societies and face risks. Therefore, community interaction between students themselves and students and the community is one of the most important standards of quality of university education.

The University is a dynamic and renewable society (new students, graduate students), which hosts students from various cultural levels. This diversity is one of the most important components of the university and its scientific, institutional, and community strength. The University is an open and interactive system (Abed \& Al-badainah, 2013). Students' values of tolerance correspond to their behavior. Hence, the aim of the current study is to identify the values held by university students in multicultural environment and contribute to the formulation of future programs and plans promoting the values of tolerance in universities.

The values of tolerance are becoming increasingly important in a world of globalization, increased human mobility between societies, and development of transport and technology. The United Arab Emirates is one of the most sought-after countries in the world because of its safe and inclusive environment. As in the country, there are the great diversity of cultures and beliefs in state universities. Therefore, the current study examines the extent to which students possess the values of tolerance, and whether this has an impact on their academic achievement and culture. Based on the above, the problem of the study is determined in the relationship between the students' possession of the values of tolerance and its relationship to academic achievement. There are the following questions:

1. What is the level of tolerance among university students?

2. Are there differences between the values of tolerance and the year of study?

3. Are there differences between the values of tolerance attributed to culture?

4. Are there differences between tolerance values attributed to gender?

5. Are there differences between the values of tolerance and the cumulative GPA? 


\section{LITERATURE REVIEW}

The present study is aimed at identifying the values owned by university students that contribute to their academic performance. Therefore, many studies have been reviewed, corresponding with the current study.

Tolerance and consideration of different ideas and points of view, even the unpalatable ones, are at the core of a pluralist, democratic order (Zhao et al., 2018).

The conducted theoretical analysis has made it possible to find that education is that milieu where the formation of a person's fundamental value and meaning attitudes take place. Further these attitudes become a leading factor of forming tolerant ethnic consciousness in the multicultural milieu of a higher education institution (Mitin et al., 2017).

The dictionary also defines tolerance as "a fair and objective attitude toward those whose opinions and practices differ from our own." (Lickona, 2006) Tolerance in this sense is an intellectual virtue as well as an ethical one. It requires an effort to be objective, to understand those who are different from ourselves, to try to rise above irrational bias, and to seek the fullness of truth in a spirit of humility.

Hameed et al. (2017) conducted a study aimed at revealing the level of social tolerance among university students and discovering the differences in social tolerance among students according to gender. The study sample consisted of (100) male and female students from the Faculty of Literature at the University of Qadisiyah in Iraq. The results of the study indicated that students have a high sense of social tolerance, and there are no statistically significant differences attributed to gender. Both have the same level of social tolerance.

Halpern (2003) also conducted a study aimed at determining whether there was a relationship between higher education and tolerance towards women, migrants and Muslims. The study sample consisted of (95) students from Henderson University, USA.

The results indicated that the relationship between the total tolerance variable and the study years was (.063), although it was positive, it was not statistically significant at the significance level 0.05 , thus, the hypothesis that tolerance increases with the level of years of higher education was rejected. However, a relationship was observed between attitudes analysis, suggesting that years of higher education may increase tolerance in specific cases. However, when the results of the younger students were examined, the result revealed a statistically significant correlation with the overall tolerance at the significance level (0.22), indicating that older students are more conservative, especially males.

Abdel-Wahab (2008) conducted a study aimed at identifying social and cultural tolerance in Egyptian society. The study sample consisted of 590 individuals. The results of the study indicated that there is no statistically significant relationship between tolerance and education level. There was a statistically significant difference in relationship to gender, i.e. males were more tolerant than females. 
Najjar et al. (2017) also conducted a study aimed at identifying the role of Al-Aqsa University in promoting the values of tolerance when asked from the point of view of students and faculty members at the Faculty of Education. To achieve this, the study was conducted on a sample of 320 students and faculty members at the university. The results of the study showed that the overall degree of the role of the university in promoting the values of tolerance from the students' point of view came with an arithmetic mean (3.22), a standard deviation (0.54) and a relative weight $(64.5 \%)$. It reached from the point of view of faculty members (3.18) and standard deviation (0.54) and a relative weight of $(63.6 \%)$. The results also showed that there are no statistically significant differences in the role of Al-Aqsa University in the development of values of tolerance according to the variables of gender and belonging. The results indicated that there are statistically significant differences for years of service among faculty members.

A study published by the American Counseling Association (ACA) (2019) was aimed to ascertain the validity of the hypothesis of a negative association between violence (intolerant behaviors) and its relationship to academic progress. The study used information from the National Center in selecting the sample of the study, which consisted of 12,144 parents of students. The results of the study indicated that students who exhibited inappropriate behaviors were those who were abused by teachers and were more likely to exhibit intolerant behaviors. Students who coexisted with their intolerant peers were more likely to exhibit similar violent reactions. The results also indicated that students living in safe environments had higher academic success rates than students living in unsafe environments.

Through the presentation of previous studies, it can be said that most studies were focused on limited values such as social tolerance and intolerance among students and its relationship to academic achievement, gender and culture. The current study will add data on the possession of students of the UAE universities of the values of tolerance, such as coexistence, cultural diversity, social responsibility, openness, acceptance of others' opinions, participation, appreciation, respect, etc., and the relationship of values to the academic performance.

\section{METHOD}

\section{Research design}

The study adopted the descriptive correlative approach (Obeidat \& AlKhaza'leh, 2019), which provides an understanding of tolerance and its relationship to the cumulative rate, where this approach examines the research variables as they are among the sample members without the role of the researcher in controlling the variables measured.

\section{Procedure}

The researcher reviewed the previous studies related to the subject of this study, as well as the psychological measurements, which helped the researcher in the design of the study tool. Then, a representative sample of 32 students from UAE universities was selected by random method, to measure the validity and reliability of the scale, and its accuracy and consistency. Several techniques were studied that were used to develop the 
elements of the research scale (Greenhow \& Burton, 2011; Hawi \& Samaha, 2017). Tolerance scale's items all had choices ranging from 0 to 15 for students to mark. The issues were agreed with the local committee on scientific ethics of Al Ain University.

\section{Study Sample}

The study population includes all UAE university students. The study sample consists of 200 male and female students from different UAE universities, of whom $18 \%$ males and $82 \%$ females, $71.5 \%$ were aged between $18-29$ years. As for the nationality (culture), it was found that $69 \%$ of the respondents were from the UAE, $7 \%$ from Jordan, $6.5 \%$ from Yemen, and the rest were distributed in close proportions among students from Syria, Egypt, Palestine, Lebanon, Tunisia, Bahrain, Somalia, Algeria, the Philippines and Canada. The study sample was distributed as follows: 50\% from Al Ain University of Science and Technology, 25\% from UAEU, 7.5\% Higher Colleges of Technology, 2\% Abu Dhabi University, 4\% Ajman University, 3\% British University in Dubai. The sample also included 2\% American University of Science and Technology, 2\% Zayed University, 2\% Dubai Islamic and Arabic College, 1.5\% Fatima College of Health Sciences, $1 \%$ New York University. As for the distribution of the study sample over the academic year, it was found that $34.5 \%$ of the study sample are students of the fourth academic year, $29 \%$ students of the second year, $2 \%$ students of the third year, and $16 \%$ of first year students. As for the professional status, $63.5 \%$ of the study sample were unoccupied students and $36.5 \%$ were students who combine work and studies.

After clarification of all issues and procedures, questionnaires were printed for distribution to students of UAE universities. Previously, permission was obtained to conduct a survey at universities. Before distributing the questionnaires, the students were explained the purpose of the study and the procedure for filling out the questionnaire. Survey participants were selected selectively during the lecture, explaining its purpose and inviting those who wish to take part in it after graduation in a separate room of the university.

About 30 minutes of time was recommended to fill out the questionnaire. Students were explained that they voluntarily participate in the study and fill out questionnaires. Anonymity and other ethical issues were duly resolved.

\section{Statistical processing}

To achieve the goals of the study and to analyze the data collected, several appropriate statistical methods were used, such as Statistical Packages for Social Sciences SPSS. After the data has been encoded and entered to the computer and then the following statistical methods were used:

1. Finding the Pearson correlation coefficient between each field and the total degree of the questionnaire to ensure the validity of the internal consistency of the questionnaire.

2. Finding the coefficient of stability using "Alpha Cronbach" to ensure the stability of the questionnaire. 
3. Using the Pearson correlation coefficient method to measure the correlation between 15 variables.

4. Using the Independent $T$ test to find the differences between the averages of only two samples.

5. Using ANOVA test to find differences between three and above averages.

\section{FINDINGS AND DISCUSSION}

\section{Presentation and analysis of the results related to the first question:}

The first question in the study states, "What is the level of tolerance among university students?"

To learn about the values of tolerance among university students, the frequencies, percentages, averages, standard deviations, and the ranks of the responses of the study sample were used to determine the values of tolerance among university students, and results are illustrated in Table 1 below.

Table 1

The responses of the study sample to the question on values of tolerance among university students

\begin{tabular}{lllll}
\hline The dimension & $\begin{array}{l}\text { Arithmetic } \\
\text { average }\end{array}$ & $\begin{array}{l}\text { Standard } \\
\text { deviation }\end{array}$ & $\begin{array}{l}\text { Relative weight } \\
(\%)\end{array}$ & Rank \\
\hline Peace (with oneself) & 2.79 & 0.58 & 93.1 & 3 \\
\hline Peace (with others) & 2.31 & 0.84 & 76.8 & 12 \\
\hline Love (sharing joy) & 2.57 & 0.69 & 85.5 & 9 \\
\hline Love (altruism) & 2.55 & 0.74 & 84.8 & 10 \\
\hline Meeting new people & 1.78 & 1.06 & 59.3 & 16 \\
\hline Softness & 2.81 & 0.48 & 93.7 & 2 \\
\hline Competitiveness & 2.89 & 0.42 & 96.3 & 1 \\
\hline Participation & 2.66 & 0.84 & 88.5 & 8 \\
\hline Assistance & 2.67 & 0.67 & 89.1 & 7 \\
\hline Social responsibility & 2.72 & 0.70 & 90.8 & 4 \\
\hline Justice & 1.91 & 1.40 & 63.5 & 14 \\
\hline Equality & 2.21 & 1.15 & 73.5 & 13 \\
\hline Respect and appreciation & 2.50 & 0.79 & 83.3 & 5 \\
\hline Openness & 2.71 & 0.67 & 90.2 & 6 \\
\hline Cultural diversity & 2.70 & 0.65 & 89.9 & 12 \\
\hline Freedom of acceptance & 2.31 & 0.94 & 76.9 & 83.5 \\
\hline Tolerance as a whole & 2.50 & 0.79 & & \\
\hline
\end{tabular}

It is clear from the previous table that the respondents have a tolerance of $83.5 \%$. In the first place stands - "Competitiveness" (96,3\%), and on the last - "Meeting new people" $(59,3 \%)$. 


\section{Presentation and analysis of the results related to the second question:}

The second question states: "Are there differences between the values of tolerance and the year of study?"

To answer this question, one-way ANOVA test was used to show the statistically significant difference between the means of three groups due to the variable of the year of study. The results are shown in Table 2 .

Table 2

Results of One-way ANOVA test depending on the year of study variable

\begin{tabular}{lllllll}
\hline The scale & $\begin{array}{l}\text { Source } \\
\text { Contrast }\end{array}$ & $\begin{array}{l}\text { Total } \\
\text { squares }\end{array}$ & $\begin{array}{l}\text { Degree of } \\
\text { freedom }\end{array}$ & $\begin{array}{l}\text { Average } \\
\text { squares }\end{array}$ & F value & Significance \\
\hline Tolerance & Between groups & 0.372 & 3 & $\mathbf{0 . 1 2 4}$ & $\mathbf{0 . 9 2 1}$ & $\mathbf{0 . 4 3 2}$ \\
\cline { 2 - 7 } & Within groups & 26.424 & 196 & $\mathbf{0 . 1 3 5}$ & & \\
\cline { 2 - 4 } & Total & 26.796 & 199 & & & \\
\hline
\end{tabular}

It is clear from the previous table that the significance value of tolerance is $(0.432)$ which is greater than the level of significance 0.05 and therefore there are no statistically significant differences in tolerance in the sample members due to the variable of the study year.

\section{Presentation and analysis of the results related to the third question:}

The third question states: "Are there differences between the values of tolerance attributed to culture?"

To answer this question, one-way ANOVA test was used to show the statistically significant difference between the means of three groups due to the culture variable, and the results are shown in Table 3.

Table 3

Results of One-way ANOVA test depending on the culture variable

\begin{tabular}{lllllll}
\hline The scale & $\begin{array}{l}\text { Source } \\
\text { Contrast }\end{array}$ & $\begin{array}{l}\text { Total } \\
\text { squares }\end{array}$ & $\begin{array}{l}\text { Degree of } \\
\text { freedom }\end{array}$ & $\begin{array}{l}\text { Average } \\
\text { squares }\end{array}$ & F value & Significance \\
\hline Tolerance & Between groups & 6.048 & 14 & $\mathbf{0 . 4 3 2}$ & 3.852 & $\mathbf{0 . 0 0 0 * *}$ \\
\cline { 2 - 8 } & Within groups & 20.748 & 185 & $\mathbf{0 . 1 1 2}$ & & \\
\cline { 2 - 7 } & Total & 26.796 & 199 & & & \\
\hline
\end{tabular}

** Statistically significant at the level of significance 0.01

It is clear from the previous table that the significance value of tolerance is 0.00 which is less than the significance level 0.05 . Consequently, there are statistically significant differences in the tolerance of the sample members due to the culture variable in favor of those who are of UAE nationality. 


\section{Presentation and analysis of the results related to the fourth question:}

The fourth question states, "Are there differences between tolerance values attributed to gender?"

To answer this question, an independent $\mathrm{T}$ - test was used to compare the means of two groups of the study sample members. The results are shown in Table 4.

Table 4

The results of the T- test depending on the gender variable

\begin{tabular}{|c|c|c|c|c|c|c|c|}
\hline The scale & Gender & $\begin{array}{l}\text { Arithmetic } \\
\text { average }\end{array}$ & $\begin{array}{l}\text { Standard } \\
\text { deviation }\end{array}$ & $\begin{array}{l}\text { Value } \\
\text { of } T\end{array}$ & $\begin{array}{ll}\begin{array}{l}\text { Degree } \\
\text { freedom }\end{array} & \\
\end{array}$ & $\overline{\text { Sig }}$ & $\begin{array}{l}\text { Significance } \\
\text { level* }\end{array}$ \\
\hline \multirow[t]{2}{*}{ Tolerance } & Male & 2.41 & 0.63 & \multirow{2}{*}{-2.224} & \multirow{2}{*}{198} & \multirow{2}{*}{0.027} & \multirow[t]{2}{*}{ Significant } \\
\hline & Female & 2.56 & 0.27 & & & & \\
\hline
\end{tabular}

* Statistically significant at the level of significance 0.01; statistically significant at the 0.05 level of significance

It is clear from the previous table that the value of the significance of 0.027 for tolerance is less than the level of significance 0.05 . Therefore, there are statistically significant differences in the tolerance in the sample members according to the gender variable. The average degree of tolerance in females is 2.56 , which is bigger than the average tolerance in males (2.41).

\section{Presentation and analysis of the results related to question 5:}

The fifth question states, "Are there differences between the values of tolerance and the cumulative GPA?" Pearson correlation coefficient was used, and the following table shows the analysis of the results of the fifth question.

Table 5

The correlation between the tolerance values and the cumulative average of the sample members

\begin{tabular}{ll}
\hline The dimension & Cumulative average \\
\hline Tolerance as a whole & $0.213^{* *}$ \\
\hline Peace (with oneself) & 0.072 \\
\hline Peace (with others) & $0.263^{* *}$ \\
\hline Assistance & $0.176^{* *}$ \\
\hline Social responsibility & 0.122 \\
\hline Respect and appreciation & 0.135 \\
\hline Openness & $0.145^{*}$ \\
\hline Cultural diversity & $0.206^{* *}$ \\
\hline Freedom of acceptance & 0.026 \\
\hline Love (sharing joy) & 0.128 \\
\hline Love (altruism) & 0.109 \\
\hline Meeting new people & 0.035 \\
\hline Competitiveness & $0.249^{* *}$ \\
\hline Softness & $0.163^{*}$ \\
\hline Participation & 0.064 \\
\hline$* *$ Statistically significant at the level of significance 0.01 \\
$*$ Statistically significant at the level of significance 0.05
\end{tabular}


From Table 5 it is clear that tolerance as a whole, peace (with others), assistance, openness, cultural diversity, competitiveness, and softness are statistically significant coefficients at a level of 0.01 or less, which means that there is a positive correlation between them and the cumulative GPA of the sample members.

This study is a preliminary assessment of the level of tolerance values among UAE university students and is aimed at statistically significant relationships and differences between the values of tolerance and the student's academic rate, cultural background, gender and academic year. These results are interpreted in the light of study variables. The following is a discussion of the study questions based on the findings:

The first question: "What is the level of tolerance among university students?" The results indicated that the level of tolerance among university students is $83.5 \%$, which can be justly considered high. This result is high because respondent students live in the UAE's multinational society (Livsey \& James, 2019). In accordance with the Hofstede's theory of cultural dimensions, the UAE residents lean toward collectivism, in other words, toward peaceful coexistence and toward an atmosphere of mutual assistance, which are important to them (Pivovarov \& Maksimtsev, 2008). In our opinion, a substantial explanation of these quantitative results lies in the fact that the UAE's pupation is polychronic and seek long-term interpersonal relations.

The second question states: "Are there differences between the values of tolerance and the study year?" The results indicated that there were no statistically significant differences between the level of tolerance values in the sample members and the study year variable. This indicates that all students at all levels have a high level of tolerance. This finding is consistent with the Halpern study, whose results indicate that tolerance does not increase with the years of study. As well as with the study of Abdel-Wahab (2008), which pointed to the absence of a relationship between tolerance and the level of education.

The third question states: "Are there differences between the values of tolerance attributed to culture?" The results indicate that there are statistically significant differences between the values of tolerance among the study sample due to the culture variable in favor of the students of Emirati nationality. This is evidence that the UAE society promotes tolerance values and higher education institutions support this. This finding differs with the study of Najjar \& Gali (2017) who did not find in their results significant differences attributed to belonging to any culture. In this case, a factor that significantly affected the results is the respondents' sense of identification with the certain culture. Representatives of the non-indigenous group who have been living in the UAE for a long time experience assimilation to the point when traditions and values of the local population become a cultural norm. However, with the expansion of the Internet around the world, foreigners who were compelled to live outside their homeland may not enter even the initial stage of acculturation. This happens because people have a constant connection with relatives and are able share information in a native language only, which reduces the number of social contacts and, accordingly, the likelihood of cultural diffusion (Ono, 2014). Assimilation surveys take time and additional resources; hence, they may be carried out in the future study. From the above, the difference 
between the research results is within the normal range, given that the present groups of respondents hypothetically have different acculturation experiences.

The fourth question states, "Are there differences between tolerance values attributed to gender?" The results indicate that there are statistically significant differences in tolerance according to the gender variable in favor of females. This finding is not consistent with the study of Najjar \& Gali (2017), that there are no differences between males and females, as well as with the study of Abdel-Wahab (2008), which indicated that males are more tolerant than females. The study of feminine and masculine values (Pivovarov \& Maksimtsev, 2008) shows a masculinity score of 53 on Hofstede's scale, which indicates the presence of both masculine (gender roles are very clear) and feminine traits (gender roles overlap) in the society. Therefore, the identified difference is linked to the ambiguous and changing status of women in the UAE, whose responses differ between samples due to different social experience.

The fifth question states, "Are there differences between the values of tolerance and the cumulative GPA?" The results indicate that there is a positive correlation between the tolerance values and the cumulative GPA. This indicates that the more an individual learns, the greater his or her tolerance values are. This finding is consistent with the study of the Association of Counseling Psychology (2019), whose results indicate that individuals with tolerance values are those with high academic rates.

The limitations of the study can be described as follows:

1. Participants could be influenced by the power of ethnocentrism, which is often used as a tool by educational institutions. Shakeebaee, Pishghadam \& Khajavy (2017) have shown a significant influence of ethnocentrism on the quality of knowledge that students receive during training.

2. In accordance with the Hofstede's theory, residents of the UAE have a high uncertainty avoidance index, incl. due to conflicts. Therefore, respondents tend to be tolerant out of necessity, to avoid conflict situations (Ay Çeviker et al., 2019). Since the nature of tolerance among respondents has not been determined, the results may require a broader interpretation, rather than absolute answers to the research questions, given on the basis of a quantitative assessment.

3. Strictness of the UAE immigration legislation, specifically difficult procedures of obtaining citizenship and residency, could affect the acculturation experience of respondents and the quality of their answers.

4. When collecting data, respondents were not isolated from each other and could be influenced by other respondents.

The present article quantitatively justifies the popular theories of cultural dimensions and provides idea about the cultural environment in the UAE. Findings are thus valuable to researchers, who study intercultural interactions and social tolerance.

\section{Research limitations}

There may be bias associated with the socially desirable answer to the questions posed regarding the values of tolerance among students regarding academic achievement. This 
phenomenon is based on the effect of social desirability bias (SDB) (Van de Mortel, 2008) Questions that are characterized by bias in the answers associated with the expectations of others, usually concern personal abilities qualities of the respondent, as well as academic success.

\section{CONCLUSION}

Intercultural tolerance among students is an important incentive for their effective learning. The results of the study revealed the level of tolerance among students of UAE universities and a statistically significant relationship and differences between the values of tolerance and student academic achievement, cultural background, gender and academic year. Data obtained also indicate a positive correlation between the values of tolerance. Moreover, as the results indicate, there are statistical differences in the tolerance level of females, which is higher than the average tolerance among males. There are statistically significant differences in tolerance among students, due to the culture variable in favor of UAE nationality.There are no statistically significant differences in tolerance among the students due to the variable of the year of study.

The United Arab Emirates, according to international development indicators, ranked first in various indicators related to tolerance. This is in line with the current study that the students of the UAE nationality have the highest degree of tolerance versus other nationalities. These are the recommendations that will maintain the spread of tolerance values in the UAE society and among university students:

1. Reinforcement strategy and modeling strategy. A concerned body should be established for monitoring persons with a high degree of tolerance and rewarding them. A body that will announce government rewards, benefits and advantages of good and tolerant behaviors for oneself and the community. With the appropriate media coverage to ensure the impact of these strategies on as many of the audience as possible.

2. Providing information through the distribution of leaflets in educational environments such as schools and universities on tolerant behavior, alerting, warning and clarifying the effects and dangers of intolerant (aggressive) or extremist behavior. As well as through advertisements in satellite channels or through social media. In addition to publishing scientific books and journals that discuss and explain the negative and dangerous effects on the individual and society of intolerant behaviors, and explain the benefits of tolerant behaviors.

3. Feedback strategy, by observing people with non-tolerant signs and manifestations who may develop into an aggressive personality, then reach them in some way, and provide them with appropriate information to be aware of the risk and effects of nontolerant or extremist behavior in particular.

\section{REFERENCES}

Abdel-Wahab, A. G. (2008). Modeling Students' Intention to Adopt E-learning: A Case from Egypt. The Electronic Journal of Information Systems in Developing Countries, 34(1), 1-13. 
Abed, S. \& Al-badainah, J. (2013). The Impact of auditor's gender on audit fees: Case of Jordanian auditors. International journal of business and management, 8(14), 127.

AL Heelah, M. (2000). Modern educational curricula - concepts, elements, foundations and processes. Dar Almaseerah publishing and printing, Amma - Jordan.

American Counseling Association (ACA) (2019) Retrieved 15 June, 2019 from https://www.emedevents.com/c/medical-conferences-2019/american-counselingassociation-aca-67th-annual-conference-and-expo-2019

Ay Çeviker, Ş., Keskin, H. K. \& Akıllı, M. (2019). Examining the Effects of Negotiation and Peer Mediation on Students' Conflict Resolution and Problem-Solving Skills. International Journal of Instruction, 12(3), 717-730.

Beketova, A. P., Kuprina, T. V. \& Petrikova, A. (2018). Development of students' intercultural communicative tolerance in the university multilingual educational environment. The Education and Science Journal, 20(2), 108-124.

Belyakova, E. G., \& Zakharova, I. G. (2019). Interaction of university students with educational content in the conditions of information educational environment. The Education and science journal, 21(3), 77-105.

Bobo, L. \& Licari, F. C. (1989). Education and political tolerance: Testing the effects of cognitive sophistication and target group affect. Public Opinion Quarterly, 53(3), 285-308.

European Commission (2015). Report of the Council and the Commission on the implementation of the Strategic framework for European cooperation in education and training (ET2020). Brussels. Retrieved 15 June, 2019 from http://ec.europa.eu/education/documents/et-2020-draft-jointreport-408-2015_en.pdf

Greenhow, C., \& Burton, L. (2011). Help from my "friends": Social capital in the social network sites of low-income students. Journal of Educational Computing Research, 45(2), 223-245.

Halpern, L. W. (2003). The Effects of Higher Education on Tolerance: An Investigation of Political and Cultural Attitudes of College Students. Academic Forum 21. Retrieved 15 June, 2019 from https://www.hsu.edu/academicforum/2003-2004

Hameed, I., Khan, A. K., Sabharwal, M., Arain, G. A. \& Hameed, I. (2017). Managing successful change efforts in the public sector: An employee's readiness for change perspective. Review of Public Personnel Administration, 0734371X17729869.

Hawi, N. S., \& Samaha, M. (2017). The relations among social media addiction, selfesteem, and life satisfaction in university students. Social Science Computer Review, 35(5), 576-586. 
Karpov, A. O. (2017). Dissonance tolerance as a new principle of the cross-cultural sustainability. Procedia-Social and Behavioral Sciences, 237, 723-730.

Lawler, K. (2005). The unique effects of forgiveness on health: An exploration of pathway. The university of Tennessee.

Lawler-Row, K. A. \& Piferi, R. L. (2006). The forgiving personality: Describing a life well lived? Personality and Individual Differences, 41(6), 1009-1020.

Lickona, T. (2016). Tolerance, diversity, and respect for conscience: The neglected issue. State University of New York at Cortland.

Livsey, J.R. (2019). Economic Diversification Through A Knowledge Based Economy In The United Arab Emirates: A Study Of Progress Toward Vision 2021. Naval postgraduate school Monterey CA Monterey United States.

Mitin, S. N., Shukshina, L. V., Bazhdanova, Y. V., Koretskaya, I. A., \& Vasyakin, B. S. (2017). Value and meaning attitudes as a factor of forming tolerant ethnic consciousness in the multicultural milieu of a higher education institution. Eurasian Journal of Analytical Chemistry, 12(7b), 1193-1200.

Najjar, Y. M, Ghaly, A. \& Attaf, M. (2017). The role of higher education in promoting the values of tolerance from the point of view of students and faculty members. Al-Aqsa University Journal (Humanities Series), 21 (1.1), 423-443.

Obeidat, B. F. \& AlKhaza'leh, M. S. (2019). Educational Experiences and perceptions of American Students toward Arab Students in the US: A Qualitative Study. Journal of Institutional Research South East Asia, 17(1).

Ono, M. (2014). Commoditisation of Lifestyle Migration. Mobilities, 10(4), 609-627.

Pettigrew, T. F. \& Tropp, L. R. (2006). A Meta-Analytic Test of Intergroup Contact Theory. Journal of Personality and Social Psychology, 90(5), 751-783.

Pivovarov, S.E. \& Maksimtsev, I.A. (2008). Comparative management. 2nd edition, Spb: Riter.

Shakeebaee, G., Pishghadam, R. \& Khajavy, G. H. (2017). Examining Ethnocentrism, Emotionalization, and Life Syllabus in Foreign Language Achievement. International Journal of Instruction, 10(4), 343-360.

UNESCO (1994). Tolerance: the threshold of peace A teaching (learning guide for education for peace, human rights and democracy). France.

Van de Mortel, T. F. (2008). Faking it: social desirability response bias in self-report research. Australian Journal of Advanced Nursing, 25(4), 40.

Yevdokimova, O.N. (2008). The Development of Tolerant Interaction skills of Students of Technical colleges: PhD Thesis. Chelyabinsk: Southern Ural State University. 
Zhao, G., \& Bindewald, B. J. (2018). Tolerance and Free Speech in Education: A Habermasian Perspective. Philosophy of Education Archive, 2018(1), 517-530.

Zolotukhin, V.M. (2001). Tolerance as a principle of behavior. Journal of Applied Psychology and Psychoanalysis, 3, 3-7.

Zrouwali, W. (2016). The role of positive psychology in confirmation of humanity of the human (analytical study). Journal of Human Sciences, (5). 